\title{
Balance and Mobility as Predictors of Post-Stroke Cognitive Impairment
}

\author{
Marie Helene Ursin ${ }^{a} \quad$ Astrid Bergland ${ }^{b}$ Brynjar Fure ${ }^{c} \quad$ Audhild Tørstad $^{a}$ \\ Arnljot Tveit $^{a}$ Hege Ihle-Hansen $^{a}$ \\ ${ }^{a}$ Bærum Hospital, Vestre Viken, Gjettum, and ${ }^{b}$ Faculty of Health Sciences, Oslo and \\ Akershus University College of Applied Sciences, and ${ }^{\mathrm{C}}$ The Norwegian Knowledge Centre \\ for the Health Services, Oslo, Norway
}

\section{Key Words}

Stroke $\cdot$ Post-stroke cognitive impairment $\cdot$ Dementia $\cdot$ Mild cognitive impairment $\cdot$ Balance . Mobility

\begin{abstract}
Background: The number of patients with cognitive impairment following stroke is increasing due to the rise in the number of stroke survivors. Health authorities highlight the need for prediction and early diagnostics. The aims of this study were to investigate if balance and mobility may predict cognitive impairment 1 year after stroke. Methods: The participants were patients with first-ever stroke or transient ischaemic attack (TIA). The exclusion criteria were pre-stroke cognitive impairment and dementia. Measurements of balance comprised the Berg Balance Scale (BBS) and the Figure of Eight test (Fig8). Mobility was measured by maximum walking speed and the Timed Up and Go test. Dementia and mild cognitive impairment were merged into a main outcome: cognitive impairment. Unadjusted and adjusted multivariate logistic regression models were performed. Results: One hundred and eighty subjects performed balance and mobility measures at baseline, and 158 participated in the follow-up; 13 died and 9 did not complete the follow-up. Two variables made a significant contribution in the adjusted analyses (Fig8, BBS). The strongest predictor of cognitive impairment was Fig8 with an odds ratio of 1.06. Conclusion: The results of Fig8 and BBS measured in the acute phase of stroke were predictors of cognitive impairment 1 year later in this cohort of firstever stroke or TIA.




\section{Introduction}

Every year, about 16 million people worldwide have a first-ever stroke [1]. Stroke considerably increases the risk of dementia, and the majority of patients suffering a stroke experience some degree of cognitive impairment [2,3]. Cognitive impairment affects secondary prevention, rehabilitation, prognosis and quality of life after stroke [4]. The mechanisms involved in post-stroke cognitive impairment include vascular cognitive disease, degenerative disease and mixed pathologies [5]. Stroke is a heterogeneous disease, with substantial variability between patients in response to treatment after stroke depending on both neural injury as well as physical function [6]. Predictors of cognitive impairment due to cerebrovascular diseases are needed in order to improve the understanding of the aetiology, cognitive decline and the patients' overall prognosis [7]. Risk factors for post-stroke cognitive decline include stroke-related factors, non-modifiable factors such as ageing, and modifiable factors such as presence of chronic vascular disease, elevated blood pressure, diabetes, obesity, smoking, alcohol and dyslipidaemia [4].

There is a growing body of evidence showing an association between physical performance and cognition $[8,9]$. The association between balance and gait and higher-level cognitive functioning can shed light on new ways to approach and understand treatment and early diagnosis of dementia [10]. Individuals with mild dementia have worse balance performance and decreased walking speed $[11,12]$. Disturbances in gait are suggested as one of the earliest predictors of dementia [13-15]. Although walking speed is a relevant predictor of health outcomes [16], there is limited research of the possible prediction of cognitive impairment. Recently, a multicentre study suggested that the motoric cognitive risk syndrome, a combined assessment of walking speed and memory, identify those at risk of developing cognitive impairment [17].

Our understanding of how to predict and prevent cognitive impairment and dementia following a stroke is limited. A systematic review confirmed the importance of early diagnostics to provide customized interventions to vulnerable persons belonging to a risk group [18]. The trend with less severe strokes [19] provides less time for the patients in the stroke unit and thereby less opportunity for the staff to uncover cognitive impairment during hospital stay [20]. Hence it is of great interest to develop easily available clinical methods that may predict cognitive impairment at an early stage after stroke in order to be able to provide appropriate recommendations on medical care before discharge.

Low-cost disease prevention and early detection have been requested by the WHO [21] to form a basis for healthy ageing. The included measures of balance and mobility represent potential tools that may be valuable in detecting vulnerable subjects. Thus, finding the strongest motor predictor of cognitive impairment is requested in order to develop potential interventions. To our knowledge, no longitudinal study has examined if balance or mobility are predictors of cognitive impairment in a sample of acute stroke patients. The aims of this study were to investigate if measures of balance and mobility in the acute phase of stroke may predict cognitive function 1 year after stroke onset.

\section{Methods}

All patients with first-ever stroke or transient ischaemic attack (TIA) admitted to the stroke unit between March 2007 and July 2008 were invited to participate in this study. The exclusion criteria were pre-stroke cognitive impairment and dementia. We excluded patients with cognitive decline as indicated by a score $\geq 3.7$ on the informant Questionnaire on Cognitive Decline in the Elderly (IQCODE) [22] and patients with a life expectancy of less than 
a year as estimated by the treating physician. In addition, all participants in this study needed results on one of the balance and mobility measures at baseline. Sociodemographic characteristics reported were gender, age, education (more or less than 9 years) and vascular risk factors. Body weight and height were measured and body mass index calculated. Blood samples were analysed for the presence of the apolipoprotein e4 allele (ApoE4) [23].

Neurological impairment was measured using the National Institutes of Health Stroke Scale (NIHSS) on the 1st day after admittance. In addition, an experienced stroke physician classified patients with ischaemic stroke according to the Trial of Org 10172 in Acute Stroke Treatment (TOAST) classification [24] and the Oxfordshire Community Stroke Project (OCSP) classification [25].

The measurements assessing balance and mobility were performed within 1 week after stroke by dedicated physiotherapists working in the stroke unit. Balance was assessed using the Berg Balance Scale (BBS) and the Figure of Eight test (Fig8). BBS rates performance on a 5-level scale from 0 (cannot perform) to 4 (normal performance) on 14 different tasks involving functional balance control, including transfer, turning and stepping [26]. The total score ranges from 0 to 56. In Fig8, the subjects were asked to walk 'the figure of eight' twice at a given speed in their normal shoes. The number of steps made outside 'the figure of eight' was recorded [27]. Mobility was measured by maximum walking speed and the Timed Up and Go test (TUG). For the maximum walking speed test, subjects walked $10 \mathrm{~m}$ from a standing still position, and the time in seconds was registered [28]. For TUG, the patient was observed and timed while rising from an armchair, walking $3 \mathrm{~m}$, turning, walking back and sitting down again [29]. BBS, TUG and maximum walking speed are commonly used to assess balance and mobility in patients who have suffered stroke, and have been tested according to reliability and validity [26, 29-32]. Fig8 has been tested for reliability [33] and has been used in other populations [27, 34].

At the 1-year follow-up, mild cognitive impairment (MCI) and dementia were diagnosed in accordance with the Guidelines at the Memory Clinic in our hospital. For dementia, we used the International Classification of Diseases 10th revision criteria [35], and for MCI the criteria outlined by Winblad et al. [36]. The diagnoses were based on the following information: the patient's medical history, the IQCODE, results of the cognitive assessments and information regarding the patient's daily functioning - all obtained at 12 months after stroke. The cognitive assessments included Mini-Mental State Examination [37], the Clock Drawing test [38], the Trail Making test A and B [39] and the 10-word test (max score 40), including delayed recall from the Repeatable Battery from the Assessment of Neuropsychological Status [40] and figures from the Alzheimer's Disease Assessment Scale-Cognitive subscale [41]. The incidence and subtypes of MCI and dementia have been reported elsewhere [5]. MCI and dementia were merged into a main outcome named cognitive impairment in the analyses of the data.

\section{Statistical Analysis}

Data were described with means and standard deviation for normally distributed variables and with proportions and percentages for categorical variables. Correlation analyses (Pearson's r) were conducted to examine the correlations between the physical performance variables. Univariate and multivariate logistic regression models were performed with the dichotomized cognitive impairment as the dependent variable and the physical performance measurements (BBS, Fig8, TUG and maximum walking speed) and covariates as independent variables. Logistic regression was fitted for each of the physical performance measurements and controlled for all significant covariates $(p<0.2)$ except independent variables correlating $>0.60$, which might interfere with the result, as inter-correlating variables [42]. We used odds ratios with 95\% confidence intervals to compare the strength of the association between the various possible predictors and the main outcome cognitive impairment after stroke. The HosmerLemeshow test for logistic regression was used to check if the model fitted the data [43]. 
Dementia

and Geriatric

Table 1. Baseline characteristics $(\mathrm{n}=180)$

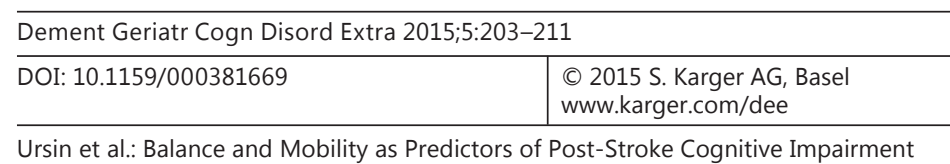

\begin{tabular}{|c|c|}
\hline \multicolumn{2}{|l|}{ Demographics } \\
\hline Age, years & $72.1 \pm 12.2$ \\
\hline Females & $88(48.1)$ \\
\hline Living arrangement, cohabitant & $122(66.7)$ \\
\hline Education $>9$ years & $140(76.5)$ \\
\hline \multicolumn{2}{|l|}{ Stroke characteristics } \\
\hline NIHSS, points & $4.3 \pm 6.5$ \\
\hline TOAST $^{1}$ & $47(26.1)$ \\
\hline $\mathrm{OCSP}^{2}$ & $42(23.3)$ \\
\hline Lesion, right & $84(46.7)$ \\
\hline \multicolumn{2}{|l|}{ Risk factors } \\
\hline BMI & $25.6 \pm 4.2$ \\
\hline Currently smoking & $39(21.3)$ \\
\hline Hypertension & $110(60.1)$ \\
\hline ApoE4 & $3(1.7)$ \\
\hline \multicolumn{2}{|l|}{ Measures of balance and mobility } \\
\hline MWS $(n=155), s$ & $8.8 \pm 2.0$ \\
\hline TUG $(n=152), s$ & $11.8 \pm 7.5$ \\
\hline Fig8 $(n=121)$, missteps & $18.1 \pm 17.8$ \\
\hline BBS $(n=178)$, points & $44.5 \pm 17.6$ \\
\hline \multicolumn{2}{|c|}{$\begin{array}{l}\text { Values are presented as } \mathrm{n}(\%) \text { or mean } \pm \text { SD. BMI = Body mass index; } \\
\text { MWS = maximum walking speed. } \\
{ }^{1} \text { Small vessel disease or other pathologies. }{ }^{2} \text { Lacunar syndromes or } \\
\text { other syndromes. }\end{array}$} \\
\hline
\end{tabular}

\section{Results}

A sample of 180 participants admitted to the hospital with first-ever stroke or TIA were included in this study. A total of 158 of these participated in the registrations 1 year later; 13 died and 9 refused or were not able to complete. The baseline characteristics are given in table 1.

The results showed that 93 (58.9\%) participants were diagnosed with cognitive impairment at the follow-up. Correlation analyses showed a high correlation between the NIHSS and the physical performance variable BBS $(r=0.75)$ and between the inter-related variables BBS, maximum walking speed, TUG and Fig8 ( $r>0.60)$. Table 2 shows the results of the logistic regression analyses, unadjusted and adjusted for significant variables except intercorrelating variables.

A full model containing all the predictors was statistically significant $\left(\chi^{2}=44.00, p<\right.$ 0.01 ). As shown in table 2 , two independent variables made a unique statistically significant contribution in the adjusted analyses (Fig8, BBS). The strongest predictor of cognitive impairment was Fig8 (odds ratio 1.06), indicating that for every additional misstep, participants were 1.06 times likely to have cognitive impairment at the follow-up.

\section{Discussion}

The present study shows that balance in the acute phase of stroke predicted cognitive impairment 1 year after stroke. Participants that performed well on Fig8 and BBS had a significantly lower risk of cognitive impairment 1 year after stroke. The results were consistent when adjusted for stroke-related factors such as neurological impairment and sociodemographic variables. Even though walking speed has been suggested as a vital sign [44] and as 
Table 2. Results of unadjusted and adjusted logistic regression of the performance measurements and covariates predicting cognitive impairment after stroke $(n=158)$

\begin{tabular}{|c|c|c|c|c|}
\hline \multirow[t]{2}{*}{ Variable, baseline } & \multicolumn{2}{|l|}{ Unadjusted } & \multicolumn{2}{|l|}{ Adjusted $^{1}$} \\
\hline & OR $(95 \% \mathrm{CI})$ & $\mathrm{p}$ & OR $(95 \% \mathrm{CI})$ & $\mathrm{p}$ \\
\hline Age (years) & $1.06(1.03-1.09)$ & $<0.001$ & $1.01(0.96-1.01)$ & 0.670 \\
\hline Gender $($ male $=0)$ & $2.12(1.11-4.05)$ & 0.024 & $1.22(0.44-3.40)$ & 0.707 \\
\hline Education $(>9$ years $=0)$ & $3.34(0.135-0.66)$ & 0.009 & $3.35(0.93-12.11)$ & 0.065 \\
\hline $\mathrm{BMI}(<25=0)$ & $0.94(0.49-1.77)$ & 0.839 & & \\
\hline Living arrangements (living alone $=0$ ) & $0.30(0.14-0.66)$ & 0.003 & $0.86(0.27-2.78)$ & 0.802 \\
\hline Smoking $($ yes $=0$ ) & $0.94(0.49-1.77)$ & 0.092 & $0.75(0.21-2.68)$ & 0.653 \\
\hline Hypertension (yes = 0) & $1.61(0.85-3.07)$ & 0.148 & $1.68(0.61-4.60)$ & 0.313 \\
\hline TOAST $($ small vessel $=0$ ) & $1.58(0.78-3.21)$ & 0.201 & & \\
\hline OCSP (lacunar syndromes $=0$ ) & $0.94(0.45-1.98)$ & 0.869 & & \\
\hline Lesion (right $=0$ ) & $1.68(0.89-3.17)$ & 0.112 & $2.40(0.89-6.48)$ & 0.085 \\
\hline ApoE4 (not having = 0) & $0.34(0.03-3.80)$ & 0.379 & & \\
\hline NIHSS (points) & $1.23(1.09-1.39)$ & 0.001 & $0.50(0.82-1.51)^{2}$ & 0.503 \\
\hline TUG (s) & $1.05(1.00-1.11)$ & 0.065 & $1.01(0.94-1.09)^{2}$ & 0.730 \\
\hline $\operatorname{MWS}(\mathrm{s})$ & $1.09(0.99-1.19)$ & 0.083 & $1.05(0.97-1.14)^{2}$ & 0.251 \\
\hline Fig8 (missteps) & $1.06(1.03-1.10)$ & $<0.001$ & $1.06(1.02-1.10)^{2}$ & 0.001 \\
\hline BBS (points) & $0.94(0.91-0.98)$ & 0.001 & $0.95(0.92-0.98)^{2}$ & 0.004 \\
\hline
\end{tabular}

$\mathrm{OR}=$ Odds ratio $\mathrm{CI}=$ confidence interval; $\mathrm{BMI}=$ body mass index; lesion = affected side of the brain; MWS = maximum walking speed.

${ }^{1}$ Adjusted for significant variables with $\mathrm{p}<0.2 .{ }^{2}$ Variables correlating $>0.6$ were excluded from the analyses.

a predictor of cognition in older people [13], maximum walking speed did not have predicting ability in this population assessed during the 1st week after stroke. TUG, the other measure of mobility, did not have the ability to predict cognitive impairment.

Executive function is associated with balance in older adults after mild stroke [45] and with falls among older people [46], which might correspond well with our results. Performance of balance such as in Fig8 and BBS involves executive functioning often linked to vascular disease and partly regulated by the prefrontal areas of the frontal lobe [47]. It has been suggested that executive functions as opposed to global cognition or memory, are important for gait and balance [48, 49]. Executive function is regarded as higher-level cognitive function, implying a control function of other cognitive functions [50]. To achieve effective goal-directed behaviour, it is not only important to be able to initiate and plan actions, but also to be flexible, to be able to shift plan and to inhibit irrelevant information or responses during action. The inherent diversity of abilities involved in executive function is naturally difficult to grasp in single assessments and entails a lack of gold standard measure. Possibly, the individual's cognitive flexibility also described as a set-shifting ability [47] is challenged when performing Fig8 and BBS.

The data did not show an association between lesions of the right side of the brain and cognitive impairment after stroke $(\mathrm{p}=0.08)$. Persons having involvement of the right side of the brain may experience an impact on visuospatial ability affecting the ability to perform the balance measures included in the study. Fig8 requires a brain function in the visuospatial networks, sensorimotor area and cerebellar functions, and it has been suggested earlier that a decrease in visuospatial performance is an indicator of cognitive decline [51]. Recent studies have assessed visuospatial memory in relation to cognitive impairment and found that such tests were able to differentiate subjects with MCI from healthy elderly subjects, but there is a 
lack of results on the potential predictive value [52]. The fact that Fig8 and BBS are associated with cognitive impairment 1 year after stroke suggests that these balance measures might be some of the earliest predictors of cognitive impairment. Fig8 and BBS are easily applicable low-cost tools that should be studied further to reveal their predictive ability.

Most other comparable studies include subjects who already are diagnosed with $\mathrm{MCI}$ or dementia, and there is a lack of studies on the predictive value of balance and mobility in stroke. Predictors of cognitive impairment after stroke are requested for better understanding of the mechanisms involved, prevention, prognosis and quality of life. In the general population, a high level of physical activity increases physical performance such as gait, mobility and balance [53]. In addition, there is a positive relationship between physical performance and cognition such as cognitive flexibility or global cognition in healthy elderly people [54]. Cognitive impairment is a risk factor for decline in physical function [55] and increased aerobic endurance may increase hippocampal volume and improve cognitive capacity in both older people with $\mathrm{MCI}$ and people without known cognitive impairment [36, 56-58]. Many forms of dementia will demonstrate motor impairment as the disease progresses due to further damage to brain tissue. Whether this applies to people who have suffered a stroke is unknown. However, balance assessed by the one-leg stance test has been shown to be an independent predictor of progression to further cognitive impairment in the early phase of dementia [59]. This is in line with the study by Pettersson et al. [12] showing that persons with mild Alzheimer's disease had a lower score on BBS and significantly more missteps in Fig8, and needed more time on TUG than healthy controls. When comparing the test results of our population with this specific study, our population in the acute phase of stroke showed similar results on TUG with a mean value of $11 \mathrm{~s}$, but worse mean scores on BBS (44.5 vs. 53 points) and Fig8 (18 vs. 13 missteps).

In the present study, the measures of maximum walking speed and TUG did not have the ability to predict cognitive impairment. Still, both maximal walking speed $(\mathrm{p}=0.08)$ and TUG ( $p=0.07)$ showed borderline significant results in the unadjusted analyses. Since this is the first study seeking to predict cognitive impairment after stroke by assessing balance and mobility in the acute phase of stroke and TIA, we are not able to compare our participants with similar populations. Our findings indicate that in the acute phase of stroke, measures including gait such as TUG and maximum walking speed are not sensitive predictors of cognitive impairment. Further knowledge of the associations between physical performance and cognition will be a strength when implementing individualized rehabilitation plans for persons with a first-ever stroke or TIA in the early rehabilitation setting. Fig8 has earlier been described as having the ability to distinguish those with the best motor functioning in the acute phase of stroke [60] regarding balance performance. These persons without severe disabilities in acute stroke will not routinely receive specific supervision after discharge, which underlines the importance of finding in this group those who are vulnerable to developing cognitive impairment. Those at high risk and their families will benefit from customized information and guidance on amendable factors [18]. The best-established protective factors include physical activity, exercise and education [61, 62]. Further studies seeking greater knowledge of targeted treatment to individuals at high risk of developing cognitive impairment would be a strength.

This study has some limitations; the study includes a quite healthy population with firstever stroke or TIA, and the results may not necessarily be transferable to other populations with more severely affected participants. Furthermore, patients suffering major strokes who were not able to complete the follow-up were excluded due to the longitudinal design. Our study includes maximal walking speed, which is considered to be a valid and reliable measure but, still it would have been a strength if we had included self-selected walking speed, which has been preferred in recent reviews [63]. The strengths of the study include the thoroughness 
of the diagnostics of cognitive impairment and the use of standardized performance-based measures at baseline, in addition to the information on ApoE4 and the affected side of the brain.

\section{Conclusion}

The performance on Fig8 and BBS in the acute phase of first-ever stroke or TIA was a predictor of cognitive impairment 1 year after stroke. These performance-based tests require brain function in the visuospatial networks, sensorimotor areas and cerebellar functions. Still, the mechanisms explaining this association between balance and cognitive functioning are not fully understood. Several issues remain to be further explicated, and further research is needed to reproduce these findings in other samples of patients with stroke. In addition, an interventional study of the potential effect of balance training on cognitive functioning would be useful for future patients.

\section{Acknowledgements}

The authors would like to thank all colleagues who contributed to the data collection in this study.

\section{References}

1 Hackett ML, Köhler S, O’Brien JT, Mead GE: Neuropsychiatric outcomes of stroke. Lancet Neurol 2014;13: 525-534.

-2 De Ronchi D, Palmer K, Pioggiosi P, Atti AR, Berardi D, Ferrari B, Dalmonte E, Fratiglioni L: The combined effect of age, education, and stroke on dementia and cognitive impairment no dementia in the elderly. Dement Geriatr Cogn Disord 2007; 24:266-273.

-3 Pendlebury ST, Chen PJ, Bull L, Silver L, Mehta Z, Rothwell PM: Methodological factors in determining rates of dementia in transient ischemic attack and stroke. I. Impact of baseline selection bias. Stroke 2015;46:641646.

4 Pendlebury ST: Dementia in patients hospitalized with stroke: rates, time course, and clinico-pathologic factors. Int J Stroke 2012;7:570-581.

5 Ihle-Hansen H, Thommessen B, Wyller TB, Engedal K, Oksengard AR, Stenset V, Loken K, Aaberg M, Fure B: Incidence and subtypes of MCI and dementia 1 year after first-ever stroke in patients without pre-existing cognitive impairment. Dement Geriatr Cogn Disord 2011;32:401-407.

6 Burke Quinlan E, Dodakian L, See J, McKenzie A, Le V, Wojnowicz M, Shahbaba B, Cramer SC: Neural function, injury, and stroke subtype predict treatment gains after stroke. Ann Neurol 2015;77:132-145.

7 Pendlebury ST: Stroke-related dementia: rates, risk factors and implications for future research. Maturitas 2009;64:165-171.

8 Volkers KM, Scherder EJ: Physical performance is associated with working memory in older people with mild to severe cognitive impairment. Biomed Res Int 2014;2014:762986.

$\rightarrow 9$ Voelcker-Rehage C, Godde B, Staudinger UM: Physical and motor fitness are both related to cognition in old age. Eur J Neurosci 2010;31:167-176.

$>10$ Scherder E, Eggermont L, Visscher C, Scheltens P, Swaab D: Understanding higher level gait disturbances in mild dementia in order to improve rehabilitation: 'last in-first out'. Neurosci Biobehav Rev 2011;35:699-714.

-11 Scherder E, Eggermont L, Swaab D, van Heuvelen M, Kamsma Y, de Greef M, van Wijck R, Mulder T: Gait in ageing and associated dementias; its relationship with cognition. Neurosci Biobehav Rev 2007;31:485-497.

$\$ 12$ Pettersson AF, Engardt M, Wahlund LO: Activity level and balance in subjects with mild Alzheimer's disease. Dement Geriatr Cogn Disord 2002;13:213-216.

13 Ramakers IH, Visser PJ, Aalten P, Boesten JH, Metsemakers JF, Jolles J, Verhey FR: Symptoms of preclinical dementia in general practice up to five years before dementia diagnosis. Dement Geriatr Cogn Disord 2007; 24:300-306.

14 Verghese J, Wang C, Lipton RB, Holtzer R, Xue X: Quantitative gait dysfunction and risk of cognitive decline and dementia. J Neurol Neurosurg Psychiatry 2007;78:929-935. 
15 Verghese J, Lipton RB, Hall CB, Kuslansky G, Katz MJ, Buschke H: Abnormality of gait as a predictor of nonAlzheimer's dementia. N Engl J Med 2002;347:1761-1768.

-16 Studenski S, Perera S, Patel K, Rosano C, Faulkner K, Inzitari M, Brach J, Chandler J, Cawthon P, Connor EB, Nevitt M, Visser M, Kritchevsky S, Badinelli S, Harris T, Newman AB, Cauley J, Ferrucci L, Guralnik J: Gait speed and survival in older adults. JAMA 2011;305:50-58.

17 Verghese J, Annweiler C, Ayers E, Barzilai N, et al: Motoric cognitive risk syndrome: multicountry prevalence and dementia risk. Neurology 2014;83:718-726.

18 Di Marco LY, Marzo A, Munoz-Ruiz M, Ikram MA, Kivipelto M, Ruefenacht D, Venneri A, Soininen H, Wanke I, Ventikos YA, Frangi AF: Modifiable lifestyle factors in dementia: a systematic review of longitudinal observational cohort studies. J Alzheimers Dis 2014;42:119-135.

19 Lackland DT, Roccella EJ, Deutsch AF, Fornage M, George MG, Howard G, Kissela BM, Kittner SJ, Lichtman JH, Lisabeth LD, Schwamm LH, Smith EE, Towfighi A: Factors influencing the decline in stroke mortality: a statement from the American Heart Association/American Stroke Association. Stroke 2014;45:315-353.

20 Organisation for Economic Co-Operation and Development: Health Data 2013: Statistics and Indicators for 30 Countries. Paris, Organisation for Economic Co-Operation and Development, 2014.

21 Prince MJ, Wu F, Guo Y, Gutierrez Robledo LM, O’Donnell M, Sullivan R, Yusuf S: The burden of disease in older people and implications for health policy and practice. Lancet 2015;385:549-562.

-22 Jorm AF, Jacomb PA: The Informant Questionnaire on Cognitive Decline in the Elderly (IQCODE): socio-demographic correlates, reliability, validity and some norms. Psychol Med 1989;19:1015-1022.

-23 Sadigh-Eteghad S, Talebi M, Farhoudi M: Association of apolipoprotein e epsilon 4 allele with sporadic late onset Alzheimer's disease. A meta-analysis. Neurosciences (Riyadh) 2012;17:321-326.

24 Adams HP Jr, Bendixen BH, Kappelle LJ, Biller J, Love BB, Gordon DL, Marsh EE 3rd: Classification of subtype of acute ischemic stroke. Definitions for use in a multicenter clinical trial. TOAST. Trial of Org 10172 in Acute Stroke Treatment. Stroke 1993;24:35-41.

25 Warlow CP: Epidemiology of stroke. Lancet 1998;352(suppl 3):SIII1-SIII4

26 Berg KO, Wood-Dauphinee SL, Williams JI, Maki B: Measuring balance in the elderly: validation of an instrument. Can J Public Health 1992;83(suppl 2):S7-S11.

27 Johansson G, Jarnlo G-B: Figure of Eight - A Balance Performance Test for Elderly Women. Lund, University of Lund, 1990.

28 Bohannon RW: Comfortable and maximum walking speed of adults aged 20-79 years: reference values and determinants. Age Ageing 1997;26:15-19.

29 Podsiadlo D, Richardson S: The timed 'Up \& Go': a test of basic functional mobility for frail elderly persons. J Am Geriatr Soc 1991;39:142-148.

-30 Berg K: Measuring balance in the elderly: preliminary development of an instrument. Physiother Can 1989; 41:304-311.

31 Halsaa KE, Brovold T, Graver V, Sandvik L, Bergland A: Assessments of interrater reliability and internal consistency of the Norwegian version of the Berg Balance Scale. Arch Phys Med Rehabil 2007;88:94-98.

-32 Wade DT, Wood VA, Heller A, Maggs J, Langton Hewer R: Walking after stroke. Measurement and recovery over the first 3 months. Scand J Rehabil Med 1987;19:25-30.

-33 Lindmark B, Lagerstrom C, Naessen T, Larsen HC, Persson I: Performance in functional balance tests during menopausal hormone replacement: a double-blind placebo-controlled study. Physiother Res Int 1999;4: 43-54.

34 Jarnlo G-B, Nordell E: Reliability of the modified figure of eight - a balance performance test for elderly women. Physiother Theory Pract 2003;19:35-43.

35 WHO: The ICD-10 Classification of Mental and Behavioural Disorders: Clinical Descriptions and Diagnostic Guidelines. Geneva, WHO, 1993.

36 Winblad B, Palmer K, Kivipelto M, Jelic V, et al: Mild cognitive impairment - beyond controversies, towards a consensus: report of the international working group on mild cognitive impairment. J Intern Med 2004;256: 240-246.

-37 Folstein MF, Folstein SE, McHugh PR: 'Mini-mental state'. A practical method for grading the cognitive state of patients for the clinician. J Psychiatr Res 1975;12:189-198.

38 Eddy JR, Sriram S: Clock-drawing and telling time as diagnostic aids. Neurology 1977;27:595.

39 Reitan RM: Validity of the trail making test as an indicator of organic brain damage. Percept Motor Skills 1958; 8:271-276.

40 Randolph C, Tierney MC, Mohr E, Chase TN: The repeatable battery for the assessment of neuropsychological status (RBANS): preliminary clinical validity. J Clin Exp Neuropsychol 1998;20:310-319.

41 Rosen WG, Mohs RC, Davis KL: A new rating scale for Alzheimer's disease. Am J Psychiatry 1984;141:13561364.

42 Pallant J: SPSS Survival Manual: A Step by Step Guide to Data Analysis Using IBM SPSS. Maidenhead, McGrawHill, 2013.

43 Altman DG: Practical Statistics for Medical Research. London, Chapman and Hall, 1991.

44 Fritz S, Lusardi M: White paper: 'walking speed: the sixth vital sign'. J Geriatr Phys Ther 2009;32:46-49.

$\$ 45$ Liu-Ambrose T, Pang MY, Eng JJ: Executive function is independently associated with performances of balance and mobility in community-dwelling older adults after mild stroke: implications for falls prevention. Cerebrovasc Dis 2007;23:203-210. 
46 Holtzer R, Friedman R, Lipton RB, Katz M, Xue X, Verghese J: The relationship between specific cognitive functions and falls in aging. Neuropsychology 2007;21:540-548.

47 Royall DR, Lauterbach EC, Cummings JL, Reeve A, Rummans TA, Kaufer DI, LaFrance WC Jr, Coffey CE: Executive control function: a review of its promise and challenges for clinical research. A report from the Committee on Research of the American Neuropsychiatric Association. J Neuropsychiatry Clin Neurosci 2002;14:377405.

48 Persad CC, Jones JL, Ashton-Miller JA, Alexander NB, Giordani B: Executive function and gait in older adults with cognitive impairment. J Gerontol A Biol Sci Med Sci 2008;63:1350-1355.

-49 Tangen GG, Engedal K, Bergland A, Moger TA, Mengshoel AM: Relationships between balance and cognition in patients with subjective cognitive impairment, mild cognitive impairment, and Alzheimer disease. Phys Ther 2014;94:1123-1134.

50 Jurado MB, Rosselli M: The elusive nature of executive functions: a review of our current understanding. Neuropsychol Rev 2007;17:213-233.

51 Buccione I, Perri R, Carlesimo GA, Fadda L, Serra L, Scalmana S, Caltagirone C: Cognitive and behavioural predictors of progression rates in Alzheimer's disease. Eur J Neurol 2007;14:440-446.

52 Perrochon A, Kemoun G, Dugue B, Berthoz A: Cognitive impairment assessment through visuospatial memory can be performed with a modified walking Corsi test using the 'magic carpet'. Dement Geriatr Cogn Dis Extra 2014;4:1-13.

-53 James BD, Boyle PA, Bennett DA, Buchman AS: Total daily activity measured with actigraphy and motor function in community-dwelling older persons with and without dementia. Alzheimer Dis Assoc Disord 2012; 26:238-245.

54 Wang L, Larson EB, Bowen JD, van Belle G: Performance-based physical function and future dementia in older people. Arch Intern Med 2006;166:1115-1120.

55 Stuck AE, Walthert JM, Nikolaus T, Bula CJ, Hohmann C, Beck JC: Risk factors for functional status decline in community-living elderly people: a systematic literature review. Soc Sci Med 1999;48:445-469.

56 Angevaren M, Aufdemkampe G, Verhaar HJ, Aleman A, Vanhees L: Physical activity and enhanced fitness to improve cognitive function in older people without known cognitive impairment. Cochrane Database Syst Rev 2008;CD005381.

57 Manly JJ, Tang MX, Schupf N, Stern Y, Vonsattel JP, Mayeux R: Frequency and course of mild cognitive impairment in a multiethnic community. Ann Neurol 2008;63:494-506.

58 Petersen RC: Clinical practice. Mild cognitive impairment. N Engl J Med 2011;364:2227-2234.

59 Rolland Y, Abellan van Kan G, Nourhashemi F, Andrieu S, Cantet C, Guyonnet-Gillette S, Vellas B: An abnormal 'one-leg balance' test predicts cognitive decline during Alzheimer's disease. J Alzheimers Dis 2009;16:525531.

60 Ursin MH, Ihle-Hansen H, Fure B, Tveit A, Bergland A: Balance and mobility in acute stroke: association with subgroups of stroke and socio-demographic characteristics. Eur J Physiother 2014;16:1-8.

61 Reitz C, Mayeux R: Alzheimer disease: epidemiology, diagnostic criteria, risk factors and biomarkers. Biochem Pharmacol 2014;88:640-651.

-62 Strand BH, Langballe EM, Rosness TA, Bergem AL, Engedal K, Nafstad P, Tell GS, Ormstad H, Tambs K, Bjertness E; GENIDEM group: Age, education and dementia-related deaths. The Norwegian Counties Study and The Cohort of Norway. J Neurol Sci 2014;345:75-82.

63 Middleton A, Fritz SL, Lusardi M: Walking speed: the functional vital sign. J Aging Phys Act 2015;23:314-322. 